\title{
SOCIAL AND ECONOMIC DEVELOPMENT OF THE STALINGRAD REGION IN 1943-1947 ${ }^{1}$
}

\author{
Ekaterina D. Vladimirova \\ Center of Documentation of the Contemporary History of the Volgograd Region, \\ Volgograd, Russian Federation
}

\begin{abstract}
The paper reveals the main directions of reconstruction works in Stalingrad and in the Stalingrad region after the end of the Stalingrad Battle. The stages of peaceful life's rebirth in the region are distinguished. The author also accounts the main events and quantitative indexes, which allow us to track the restoring process. It is determined that the basic reconstruction works in the region were accomplished to 1947 , and since that the process of further social and economic development of the Stalingrad region had begun. The author notes the contribution of the Stalingrad Group of Troops to the restoration of city and region's economy after the end of the Stalingrad Battle. The restoration of social and cultural scopes of the region, such as housing stock, education and culture institutions, healthcare, and some religious organizations, is also analyzed.

The author also analyzes the restoring process of the city of Stalingrad in the postwar years, determines the stages of city's economy building. It is revealed that during the restoration work local authorities paid special attention to the creation of new schools, hospitals, specialized institutes and cultural institutions in order to create a comfortable urban environment.

Key words: Great Patriotic War, restoring, industry, social sphere, Stalingrad region.

Citation. Vladimirova E.D. Social and Economic Development of the Stalingrad Region in 1943-1947. Vestnik Volgogradskogo gosudarstvennogo universiteta. Seriya 4, Istoriya. Regionovedenie. Mezhdunarodnye otnosheniya [Science Journal of Volgograd State University. History. Area Studies. International Relations], 2018, vol. 23, no. 1, pp. 138-143. (in Russian). DOI: https://doi.org/10.15688/jvolsu4.2018.1.13
\end{abstract}

УДК 94(47+57):338.246.8

ББК 63.3(2Р-4Вог)622,12

Дата поступления статьи: 07.08.2017

Дата принятия статьи: 21.11.2017

\section{СОЦИАЛЬНО-ЭКОНОМИЧЕСКОЕ РАЗВИТИЕ СТАЛИНГРАДСКОЙ ОБЛАСТИ В 1943-1947 ГОДАХ ${ }^{1}$}

\section{Екатерина Денисовна Владимирова}

Центр документации новейшей истории Волгоградской области, г. Волгоград, Российская Федерация

\footnotetext{
Аннотация. В статье комплексно рассматриваются основные направления восстановительных работ в Сталинграде и области после окончания Сталинградской битвы. Выделяются этапы возрождения мирной жизни в регионе, перечисляются основные мероприятия, приводятся количественные показатели, позволяющие наглядно проследить процесс восстановления. Определено, что к 1947 г. в регионе были выполнены $\infty$ основные восстановительные работы, начался процесс дальнейшего социально-экономического развития ㄱ. Сталинградской области. Отмечен вклад Сталинградской группы войск в восстановление хозяйства города и ஓं области после окончания битвы.

Проанализирован процесс восстановления г. Сталинграда в послевоенные годы, определены этапы строительства городского хозяйства. Установлено, что в ходе восстановительных работ местные власти обращали особое внимание на создание новых школ, больниц, профильных институтов и учреждений культуры для создания комфортной городской среды обитания.

Ключевые слова: Великая Отечественная война, восстановление, промышленность, социальная сфера, Сталинградская область.
} 
Цитирование. Владимирова Е. Д. Социально-экономическое развитие Сталинградской области в 19431947 годах // Вестник Волгоградского государственного университета. Серия 4, История. Регионоведение. Международные отношения. - 2018. - Т. 23, № 1. - C. 138-143. - DOI: https://doi.org/10.15688/jvolsu4.2018.1.13

Сталинград стал одним из первых городов, возрождение которого проходило в условиях продолжавшихся военных действий. Нижней хронологической границей статьи выбран 1943 г. - окончание Сталинградской битвы и начало восстановительного периода. Верхней хронологической границей является 1947 г. - к этому времени были проведены основные мероприятия по восстановлению мирной жизни в регионе, завершилось возрождение основных культурных центров г. Сталинграда и области.

В 1943 г. ущерб, нанесенный захватчиками, по приблизительным подсчетам оценивался в 11,5 млрд руб., позднее цифры возросли до 19,2 млрд руб., из которых 9 млрд пришлось на долю г. Сталинграда (см. таблицу) $[4$, с. 75$]$.

Первые шаги в восстановлении хозяйственных объектов города и области были сделаны Сталинградской группой войск. Одной из задач, поставленных перед этим воинским формированием, было проведение восстановительных работ. Группа занималась разминированием территорий и объектов, уборкой трупов, ремонтом дорог, очисткой колодцев [3, с. 318$]$.

Еще одной проблемой была острая нехватка рабочих рук. По данным Городского статистического комитета (далее - ГСК), в феврале 1943 г. в городе насчитывалось 32 тыс. 181 чел. населения [9, с. 457]. Однако мирные жители также внесли огромный вклад в возрождение города и области. Одним из проявлений такой деятельности стало черкасовс- кое движение, зародившееся в июне 1943 года. О масштабах деятельности движения позволяют судить следующие данные источников: «только в первые 3 месяца своего существования участники черкасовского движения отремонтировали и восстановили около 300 жилых домов, школ, детских садов, лечебных и других культурно-бытовых учреждений. Кроме того, они оказывали большую помощь в восстановлении заводов, фабрик, жилищнокоммунального хозяйства» [1, с. 37].

После окончания Сталинградской битвы бывшие поля сражений были переполнены неразорвавшимися снарядами, на земле лежало множество трупов погибших. Поэтому первоочередными мероприятиями стали разминирование объектов и территории, захоронение трупов, ремонт дорог и жизненно значимых объектов. Это было необходимо выполнить в кратчайшие сроки для нормализации повседневной жизнедеятельности населения города и области [5, л. 27]. Параллельно с этим шло восстановление промышленности г. Сталинграда и области. Город являлся важным промышленным центром, и в условиях продолжающейся войны было необходимо как можно быстрее восстановить его производственный потенциал. О важности и срочности ввода в строй основных промышленных предприятий Сталинграда говорит тот факт, что по решению ГКО они финансировались Промбанком без проектов и смет по фактическим затратам [6, с. 50]. Уже 20 января 1943 г. вышло постановление Государственного Комитета Обороны (далее - ГКО) № 2777с «Об орга-

Ущерб, причиненный фашистскими захватчиками г. Сталинграду и Сталинградской области

\begin{tabular}{|l|c|}
\hline \multicolumn{1}{|c|}{ Причинен ущерб } & Размер, тыс. руб. \\
\hline Гражданам области & 5298843,5 \\
\hline Колхозам области (30 районов) & 2693360,3 \\
\hline Промышленности союзного и республиканского подчинения & 1906677,2 \\
\hline $\begin{array}{l}\text { Здравоохранению, народному образованию, торговой сети и } \\
\text { промышленности областного подчинения }\end{array}$ & 2405226,8 \\
\hline $\begin{array}{l}\text { Коммунальному хозяйству (в том числе и ведомственному) } \\
\text { г. Сталинграда }\end{array}$ & 6882842 \\
\hline \multicolumn{1}{|l}{ Итого } \\
\hline
\end{tabular}

Примечание. Источник : [4, с. 75] 
низации ремонта танков на заводе № 264 в Сталинграде» [8, с. 64].

Еще одним важным промышленным объектом являлся Химпром. 14 февраля 1943 г. ГКО принял постановление № $2895 \mathrm{cc}$ «О восстановлении завода № 91 НКХП в г. Сталинграде», согласно которому первую очередь завода следовало запустить 1 июня 1943 года.

Строительно-монтажные работы на всей территории завода были развернуты в марте 1943 года. В целом срок начала эксплуатации был выдержан, однако, длительное время существовали проблемы с обеспеченностью предприятий сырьем и возвращением на рабочие места специалистов. К 24 мая 1943 г. из 800 чел., эвакуированных ранее, на Химпром вернулось только 180 работников. 26 сентября 1943 г. ГКО принял специальное постановление о восстановлении второй очереди предприятия. Оно проходило неудовлетворительными темпами. Многие строительные организации снимались с объекта и перекидывались на другие, что нашло отражение в постановлениях СГКО. Но, несмотря на трудности, планы по выпуску продукции перевыполнялись.

К 1 июня 1943 г. было открыто регулярное железнодорожное сообщение с Москвой и пригородное круглосуточное движение, налажена работа хлебопекарен и районных пищекомбинатов города, реконструированы мельницы, приступили к работе швейная и обувная фабрики, кожзавод и 30 артелей промкооперации и кооперации инвалидов по обслуживанию бытовых нужд населения. Восстановление производственной инфраструктуры: энергокомбината, линий электропередачи, транспорта - создало условия для быстрейшего возрождения промышленных предприятий [6, с. 42].

Анализ решений центральных и местных органов власти позволил сделать вывод о том, что на первом этапе восстановительных работ в Сталинграде обеспечение промышленных предприятий основными фондами осуществлялось главным образом за счет ремонта оборудования, менее пострадавшего в ходе боев [2, с. 9]. В целом основные фонды по всем предприятиям Сталинграда в 1943 г. составили около $45 \%$ от уровня 1940 г. [2, с. 8].

В проекте постановления СНК СССР «О плане развития народного хозяйства По- волжья на 1943-1947 гг.» одной из важнейших задач названо восстановление крупнейшего примышленного центра Поволжья и СССР города Сталинграда [7, л. 9]. Восстановление проходило под жестким контролем со стороны центральных органов власти. Однако по мере улучшения обстановки все больше полномочий передавалось в руки местных властей. С весны 1944 г. главным в работе СГКО стала координация усилий в восстановлении Сталинграда как промышленного областного центра и постепенная передача функций управления городом и производством в руки местных партийных и советских органов власти [9, с. 18]. Уже к 1946 г. по Сталинградским предприятиям удалось достичь довоенного уровня производства.

Второй этап восстановления и развития промышленности Сталинграда, начавшийся в 1945 г., характеризуется коренным обновлением основных производственных фондов, что было вызвано переходом предприятий на выпуск новых видов продукции или продукции новых модификаций и марок. Так, еще с июля 1944 г. Сталинградский тракторный завод (далее - СТ3) и завод № 264 перешли на производство танка Т-44 - новой модели, которая по всем характеристикам превосходила Т-34.

С 1945 г. особую роль в восстановлении предприятий города начали играть репарационные поставки оборудования из Германии. К ноябрю 1945 г. в Сталинград и Сталинградскую область было отправлено 32 предприятия и склада оборудования [2, с. 15]. Основная часть репараций поступила в 19451947 годах. Демонтаж заводов в Германии проводился до января 1947 года. Однако в целом репарации не сыграли решающей роли в восстановлении промышленности Сталинграда. Исключением являются заводы, задействованные для производства танков и узлов для них. Речь идет о СТЗ, заводе № 264 «Судоверфь» и артиллерийском заводе № 221 «Баррикады». Именно поступившее из Германии оборудование позволило этим предприятиям нарастить свои производственные мощности в объемах от 16 до $50 \%$.

В целом к 1947 г. промышленность Сталинграда и Сталинградской области была полностью восстановлена. По выпуску валовой 
продукции достигли довоенного уровня (1940 г.) завод тракторных деталей и нормалей (1947 г.), СталГРЭС (1948 г.), СТЗ, заводы медоборудования и № 91 (1949 г.). На 1 июля 1950 г. ситуация сложилась следующим образом: за период с 1946-1950 гг. в эксплуатацию введено 387503 кв. м производственных площадей. На СТЗ восстановлены все цеха завода. На заводе «Красный Октябрь» функционировало 16 мартеновских печей, запущены все работавшие до войны прокатные станы. На заводе «Баррикады» введено в эксплуатацию 76171 кв. м производственных площадей. Полностью восстановлены заводы тракторных деталей и нормалей, № 91, гидролизный и др. Построены также кислородный завод, завод им. Петрова, введен в эксплуатацию ремонтно-подшипниковый завод [1, с. 28-29].

Несмотря на важность восстановления промышленного производства, власть большое внимание уделяла возрождению социальной и культурной сфер. Например, в Постановлении ГКО от 4 апреля 1943 г. № $3117 \mathrm{c}$ «О первоочередных мероприятиях по восстановлению Сталинграда и Сталинградской области» в сфере культурно-бытового обслуживания предполагалось в кратчайшие сроки восстановить Сталинградский медицинский институт, 33 школы (из них 8 - в г. Сталинграде и 25 - в районах области) [8, с. 102]. Кроме того, планировалось восстановление Сталинградского драматического театра. Для этой цели выделялись ассигнования на сумму 1,5 млн рублей [3, с. 321; 8, с. 102].

В 1943-1945 гг. происходило восстановление основной медицинской инфраструктуры города - в частности, был восстановлен Сталинградский медицинский институт, занятия в котором возобновились с 1 сентября 1943 г. [3, с. 320]. Кроме того, Наркомат здравоохранения СССР обязывался предоставить Сталинградской области для работы на постоянной основе 175 врачей. В результате восстановительных работ было воссоздано несколько городских больниц, становился возможным амбулаторный прием местного населения.

Необходимо отметить, что цели по восстановлению объектов социального назначения были достигнуты. Об этом позволяет су- дить отчетный доклад секретаря обкома ВКП(б) В.Т. Прохватилова о работе Сталинградского горкома ВКП(б) за период с 1 марта 1940 г. по 1 января 1948 года. Он приводит следующие цифры: «С 1943 по 1947 гг. включительно в городе восстановлено и построено вновь 858,4 тыс. кв. м жилья. Если прибавить к этому 175,3 тыс. кв. м жилья, сохранившегося в Кировском и Красноармейском районах, то жилой фонд составил 1 млн 33 тыс. кв. м. На январь 1948 г. в городе было: 38 км трамвайного пути, 61 пассажирский и 6 грузовых трамвайных вагонов, центральный и северный водопровод с общей мощностью подачи 13 млн кубометров воды в год. Работало 28 бань на 1409 помывочных мест, 20 амбулаторий и поликлиник на 308 врачебных приемов, 111 детских учреждений, в том числе: 82 детских сада на 411 мест и 29 детских яслей на 1870 мест. Восстановлены 72 школы на 21175 мест и 14 больниц на 2110 мест. При предприятиях и стройорганизациях восстановлено и построено 30 клубов, восстановлен и работает драмтеатр; в помещении клуба СТЗ размещался театр музкомедии» [1, с. 26-27].

Подводя итог, можно сказать, что восстановление г. Сталинграда и области после окончания Сталинградской битвы шло быстрыми темпами. Помощь в этом оказывала вся страна - оборудованием, продуктами питания, стройматериалами и т. д. В условиях острой нехватки кадров сюда ехали рабочие и специалисты. Стоит особо отметить вклад Сталинградской группы войск, бойцы которой выполнили важные подготовительные мероприятия на начальном этапе восстановления. К 1947 г. основные задачи восстановления были решены, по многим параметрам регион достиг довоенных показателей. Одной из причин такого успеха стала организация комплексного восстановления города во всех сферах жизни - как в социальной, экономической, так и в культурной.

\section{ПРИМЕЧАНИЕ}

1 Исследование выполнено за счет гранта Российского фонда фундаментальных исследований и Администрации Волгоградской области (проект №16-11-34006 «Сталинградская группа войск. 1943-1944 гг.»). 


\section{СПИСОК ЛИТЕРАТУРЫ}

1. Восстановление Сталинграда: события и факты. 1943-1951 гг. : сб. док. и материалов из фондов ГУ «Центр документации новейшей истории Волгоградской области». - Волгоград : Михаил, 2007. -64 c.

2. Восстановление экономики Сталинградской области. Репарационные поставки. 1945-1947 : док. и материалы / под ред. М. М. Загорулько. Волгоград : Издатель, 2016. - 240 с.

3. Гоманенко, О. А. Возвращение населения г. Сталинграда и области к мирной жизни после окончания Сталинградской битвы / О. А. Гоманенко, Е. Л. Головина, Е. Д. Владимирова // Экстремальное в повседневной жизни населения России: региональный аспект (к 100-летию Русской революции 1917 г.) : материалы Междунар. науч. конф. (1618 марта 2017 г.). - СПб. : Культурно-просветительское товарищество, 2017. - С. 317-322.

4. Гузев, М. М. Экономическая эксплуатация оккупированных районов Сталинградской области / М. М. Гузев, Е. Д. Владимирова // Вопросы новой экономики - 2016. - № 2 (38). - С. 71-76.

5. Краткая политическая и экономическая характеристика города Сталинграда от 13 февраля 1945 г. // Архив Управления ФСБ РФ по Волгоградской области. - Ф. 2. - Оп. 17. - Д. 17.

6. Кузьмина, Э. В. Восстановление Сталинграда. 1943-1950 / Э. В. Кузьмина. - Волгоград : Издатель, 2002. - 144 с.

7. Проект постановления СНК СССР «О плане развития народного хозяйства Поволжья на 19431947 гг.» // Российский государственный архив экономики. - Ф. 4372. - Оп. 93. - Д. 1346.

8. Сталинградская область в постановлениях Государственного Комитета Обороны (1943-1945) : док. и материалы. - Волгоград : Издатель, 2011. - 788 с.

9. Сталинградский городской комитет Обороны в годы Великой Отечественной войны : док. и материалы. - Волгоград : Издатель, 2003. - 920 с.

\section{REFERENCES}

1. Vosstanovlenie Stalingrada: sobytiya i fakty. 1943-1951 gg.: sb. dok. i materialov iz fondov GU "Tsentr dokumentatsii noveyshey istorii Volgogradskoy oblasti» [Restoration of Stalingrad: Events and Facts. 1943-1951: Collected Documents from the Funds of State Archive "The Center of Documentation of the Contemporary History of the Volgograd Region"]. Volgograd, Mikhail Publ., 2007.64 p.

2. Zagorulko M.M., ed. Vosstanovlenie ekonomiki Stalingradskoy oblasti. Reparatsionnye postavki. 1945-1947: dok. i materialy [Restoration of Staligrad Region's Economy. Reparation Supplies. 1945-1947. Documents and Materials]. Volgograd, Izdatel Publ., 2016. 240 p.

3. GomanenkoO.A., Golovina E.L., VladimirovaE.D. Vozvrashchenie naseleniya g. Stalingrada i oblasti k mirnoy zhizni posle okonchaniya Stalingradskoy bitvy [Return of Stalingrad City and Stalingrad Region Population to Peaceful Life after the End of the Stalingrad Battle]. Ekstremalnoe v povsednevnoy zhizni naseleniya Rossii: regionalnyy aspekt ( $k$ 100letiyu Russkoy revolyutsii 1917 g.): materialy Mezhdunar. nauch. konf. (16-18 marta 2017 g.) [The Extreme in Everyday Life of Russian Population: Regional Aspect (to the $100^{\text {th }}$ Anniversary of the Russian Revolution of 1917): Materials of the International Academic Conference (March 16-18, 2017)]. Saint Petersburg, Kulturno-prosvetitelskoe tovarishchestvo Publ., 2017, pp. 317-322.

4. GuzevM.M., Vladimirova E.D. Ekonomicheskaya ekspluatatsiya okkupirovannykh rayonov Stalingradskoy oblasti [Economic Exploitation of Stalingrad Region's Occupied Districts]. Voprosy novoy ekonomiki, 2016, no. 2(38), pp. 71-76.

5. Kratkaya politicheskaya i ekonomicheskaya kharakteristika goroda Stalingrada ot 13 fevralya 1945 g. [Brief Political and Economic Characteristics of the City of Stalingrad of February 13, 1945]. Arkhiv Upravleniya FSB RF po Volgogradskoy oblasti [Archive of the Department of the Federal Security Service of the Russian Federation for the Volgograd Region], F. 2, Op. 17, D. 17.

6. Kuzmina E.V. Vosstanovlenie Stalingrada. 1943-1950 [Restoration of Stalingrad. 1943-1950]. Volgograd, Izdatel Publ., 2002. 144 p.

7. Proekt postanovleniya SNK SSSR «O plane razvitiya narodnogo khozyaystva Povolzhya na 19431947 gg.» [Draft Resolution of the Council of Peoples' Commissars of the USSR "On the Development Plan for the National Economy of the Volga Region for 19431947"]. Rossiyskiy gosudarstvennyy arkhiv ekonomiki [Russian State Archive of Economy], F. 4372, Op. 93, D. 1346.

8. Stalingradskaya oblast $v$ postanovleniyakh Gosudarstvennogo Komiteta Oborony (1943-1945): dok. $i$ materialy [The Stalingrad Region in the Reolutions of State Defense Committee (1943-1945): Documents and Materials]. Volgograd, Izdatel Publ., 2011. 788 p.

9. Stalingradskiy gorodskoy komitet Oborony v gody Velikoy Otechestvennoy voyny: dok. $i$ materialy [Stalingrad Defense Committee During the Great Patriotic War: Documents and Materials]. Volgograd, Izdatel Publ., 2003. 920 p. 
Е.Д. Владимирова. Социально-экономическое развитие Сталинградской области в 1943-1947 годах

\section{Information About the Author}

Ekaterina D. Vladimirova, Chief Specialist of Science \& Research Department, Center of Documentation of the Contemporary History of the Volgograd Region, Dymchenko St., 16, 400005 Volgograd, Russian Federation, evladimirova90@gmail.com, https://orcid.org/0000-0002-8136-7474

\section{Информация об авторе}

Екатерина Денисовна Владимирова, главный специалист отдела научно-исследовательской работы, Центр документации новейшей истории Волгоградской области, ул. Дымченко, 16, 400005 г. Волгоград, Российская Федерация, evladimirova90@gmail.com, https://orcid.org/0000-0002$8136-7474$ 